http://www.jfas.info

\title{
EFFECTS OF DRYING CONDITIONS ON THE PHYSICOCHEMICAL AND FUNCTIONAL PROPERTIES OF RED- AND YELLOW-FLESHED WATERMELON RINDS FLOUR
}

\author{
L. H. Ho ${ }^{1, *}$, W. P. Pang ${ }^{1}$, T. C. Tan ${ }^{2}$ and K. A. Mustafa ${ }^{1}$ \\ ${ }^{1}$ Department of Food Industry, Faculty of Bioresources and Food Industry, Universiti Sultan \\ Zainal Abidin, 22200 Besut, Terengganu, Malaysia \\ ${ }^{2}$ Food Technology Division, School of Industrial Technology, Universiti Sains Malaysia, \\ 11800, Penang, Malaysia
}

Published online: 08 August 2017

\begin{abstract}
This study aimed to investigate the effect of drying conditions (freeze drying and hot-air oven drying at 40 and $60^{\circ} \mathrm{C}$ ) on the physicochemical and functional properties of red and yellow-fleshed watermelon rind flour. In comparison among the drying processes used in this study, freeze drying method resulted in flour with better quality in terms of colour, $\mathrm{pH}$, total titratable acids, total sugar, total starch and digestible starch. However, results on the physicochemical and functional attributes of the flours revealed that hot-air dried flour had higher values for bulk density, water absorption capacity, oil absorption capacity and resistant starch than that of the freeze dried flour. Drying conditions exerted marked effects on the properties of watermelon rind flours in this study.
\end{abstract}

Keywords: watermelon rind flour; hot-air oven drying; freeze drying; physicochemical properties; functional properties.

Author Correspondence, e-mail: holeehoon@unisza.edu.my

doi: http://dx.doi.org/10.4314/jfas.v9i2s.58 


\section{INTRODUCTION}

Watermelon, Citrullus lanatus belongs to the Cucurbitaceae family and has been known for centuries to have a positive effect on human health. The fruit shape is most commonly round to elongated and has a smooth, hard exterior rind (exocarp) which range from light to dark green with a usually red or sometimes yellow juicy, sweet interior flesh (mesocarp and endocarp). According to [1], watermelon is a rich source of vitamins (i.e. vitamin A and C) and also serves as a good source of phytochemicals (i.e. lycopene and carotenoids). Watermelon is one of the most abundant fruit and its juice is commercially produced worldwide for human consumption, hence generating a vast amount of solid waste, i.e. rinds and seeds. The rinds remain as one of the important food grade agro-wastes generated by many restaurants, cottage fruit juice producers and food industries across Southeast Asia and in particularly Malaysia [2]. Watermelon rinds constitutes nearly a third of the watermelon weight, thus, development of value-added products from these rinds would be of great interest to the industries. The use of whole fruit in watermelon processing is essential in order to reduce resource wastage and costs, and provide a solution to the pollution associated with this process. Many studies had been conducted and show that the rinds has potential for value-added ingredient after processing (i.e. drying) and utilization in the pharmaceuticals industries, e.g. in the preparation of bakery products or as a natural food additive [2-4].

Watermelon rinds have a moisture content of $95 \%$ (wet basis), thus making it highly perishable and susceptible to deterioration when it is in its fresh state [5]. The reduction of moisture content and water activity $\left(a_{w}\right)$ to safe levels will slow down or inhibits microbial growth and enzymatic activity, thereby extending the shelf life of the rinds. The most popular drying method used in food industry is conventional hot-air drying due to its low cost of processing [6-7]. Apart from conventional air drying, other commonly used drying methods applied in food industry include vacuum-, spray- and freeze drying [8]. Freeze drying is one of the most sought after dehydration methods, which produces supreme product quality in terms of excellent retention of nutrients, flavour and aroma and physical and sensory characteristics. However, it is often associated with low production rate and the operational cost of this process is often very high. Most pharmaceutical and nutraceutical industries can afford the freeze 
drying process due to their high cost products. In contrary, food industry tends to look for products with desired functional properties with moderate cost [9].

Though dehydrated products have commonly been obtained by hot-air drying, which allows rapid and massive processing, as well as production of a sufficiently shelf stable product. Nonetheless, the maintenance of nutritional and commercial quality of such products through this process presents some problems [10-11]. The fruit drying conditions in particularly the drying temperature, time and methods had been reported to play a significant role in affecting the physicochemical properties, functional qualities, nutritional values as well as the microbiological qualities of the fruit flour and consequently their overall qualities [9, 12-15]. Flour properties and qualities are of great concern, as these ultimately determine the usefulness of the flour in industrial applications.

Taking into account the potential utilization of watermelon rinds in industrial applications and the fact that knowledge on the effect of different drying approaches employed on the functional and physicochemical characteristics of watermelon rind flour is yet to be available. Therefore, the present study aimed to investigate the effect of the drying conditions on the physicochemical and functional properties of this flour. As a result of such investigations, depending on the desired final product quality and other considerations, a suitable drying technique can be chosen. The results should also serve as a guide for the industrial to determine the suitability of the watermelon rind flour for their applications based on its functional and physicochemical properties.

\section{RESULTS AND DISCUSSION}

\subsection{Colour}

The average values of the colour parameters of all the watermelon rind flour samples prepared by different drying treatments are presented in Table 1 . The obtained results indicated that all colour values of the flour samples prepared by different drying treatments differed significantly from each other $(\mathrm{P}<0.05)$. Comparing the different drying treatments, the $\mathrm{L}^{*}$ values of flours (both red and yellow varieties) produced by hot-air oven drying at $60^{\circ} \mathrm{C}$ appears to be lower in relation to the other drying treatments employed. Hot-air oven drying 
at $60^{\circ} \mathrm{C}$ had turned the red variety watermelon rind flour slightly darker, redder and yellower ( $\mathrm{L}^{*}, \mathrm{a}^{*}$ and $\mathrm{b}^{*}$ values of $40.26,3.41$ and 17.67). Considering the more positive value of $\mathrm{a}^{*}$ for the red variety watermelon rind flour, this indicates that the light greenish colour of the watermelon rind disappeared with drying at $60^{\circ} \mathrm{C}$. It is well-known that watermelon rind is light greenish in colour due to the presence of the naturally occurring pigments, chlorophylls (green). Chlorophylls are very sensitive to heat, hence heating at high temperature will cause degradation of these pigments and the effect is more prevalence at higher temperature as shown in present study. The higher $\mathrm{a}^{*}$ values also indicates the occurrence of non-enzymatic reaction, e.g. Maillard reaction. The increase in drying temperature led to rise of non-enzymatic browning reactions and thus produced darker coloured flour samples [16-17].

Table 1. Effect of different drying conditions on the colour properties of watermelon rind flours

\begin{tabular}{cccc}
\hline Sample $^{1}$ & \multicolumn{3}{c}{ Colour } \\
& $\mathrm{L}^{*}$ & $\mathrm{a}^{*}$ & $\mathrm{~b}^{*}$ \\
\hline R40 & $50.76^{\mathrm{b}} \pm 0.57$ & $-2.79^{\mathrm{b}} \pm 0.09$ & $14.29^{\mathrm{a}} \pm 0.21$ \\
R60 & $40.26^{\mathrm{a}} \pm 0.28$ & $3.41^{\mathrm{c}} \pm 0.05$ & $17.67^{\mathrm{c}} \pm 0.19$ \\
RFD & $57.83^{\mathrm{c}} \pm 0.81$ & $-3.47^{\mathrm{a}} \pm 0.04$ & $15.40^{\mathrm{b}} \pm 0.35$ \\
Y40 & $49.71^{\mathrm{b}} \pm 0.15$ & $-2.60^{\mathrm{c}} \pm 0.11$ & $14.03^{\mathrm{a}} \pm 0.36$ \\
Y60 & $45.06^{\mathrm{a}} \pm 0.49$ & $-1.91^{\mathrm{b}} \pm 0.10$ & $16.49^{\mathrm{c}} \pm 0.11$ \\
YFD & $53.43^{\mathrm{c}} \pm 0.08$ & $-4.84^{\mathrm{a}} \pm 0.04$ & $14.85^{\mathrm{b}} \pm 0.24$ \\
\hline
\end{tabular}

${ }^{1} \mathrm{R} 40$ and $\mathrm{R} 60$ represent red-fleshed watermelon rind flour produced by drying at 40 and $60^{\circ} \mathrm{C}$ respectively. Y40 and Y60 represent yellow-fleshed watermelon rind flour produced by drying at 40 and $60^{\circ} \mathrm{C}$ respectively. RFD and YFD represent red and yellow-fleshed watermelon rind flour respectively produced by drying in a freeze dryer.

Presented data are mean values of three replications \pm standard deviation.

Mean values in the same column with different superscript letters are significantly different ( $p$ $<0.05)$.

The freeze dried flours practically present the highest degree of lightness and the lowest degree of redness $\left(L^{*}=57.83, a^{*}=-3.47\right.$ for red variety; $L^{*}=53.43, a^{*}=-4.84$ for yellow 
variety). Similarly, in [18] also demonstrated that when comparing the different drying treatments, freeze drying produced lighter colour of pumpkin flours as indicated by higher $\mathrm{L}^{*}$ values (as compared to hot air-drying technique). Therefore, it can be concluded that freeze drying is the best drying method to preserve the colour of the watermelon rind flours without causing major colour deterioration and non-enzymatic browning when compared with convective drying methods tested. This is expected as non-enzymatic browning reaction is minimized by the low temperature used in the freeze drying.

\subsection{Water Activity $\left(a_{w}\right)$}

Water activity $\left(a_{w}\right)$ is one of the most critical factors in determining quality and safety of the foods. This value indicates how tightly water is bound, structurally or chemically within a substance. Thus, $\mathrm{a}_{\mathrm{w}}$ is a better indicator of perishability than moisture content, which simply determines the total amount of water present in a sample [19]. Table 2 shows the average values obtained for the $a_{w}$ of all the watermelon rind flour samples prepared by different drying treatments in this study.

Table 2. Effect of different drying conditions on the water activity of watermelon rind flours

\begin{tabular}{cc} 
Sample $^{1}$ & Water Activity \\
\hline R40 & $0.49^{\mathrm{b}} \pm 0.00$ \\
R60 & $0.45^{\mathrm{a}} \pm 0.00$ \\
RFD & $0.49^{\mathrm{b}} \pm 0.00$ \\
Y40 & $0.48^{\mathrm{b}} \pm 0.00$ \\
Y60 & $0.47^{\mathrm{a}} \pm 0.00$ \\
YFD & $0.48^{\mathrm{b}} \pm 0.00$
\end{tabular}

${ }^{1} \mathrm{R} 40$ and R60 represent red-fleshed watermelon rind flour produced by drying at 40 and $60^{\circ} \mathrm{C}$ respectively. Y40 and Y60 represent yellow-fleshed watermelon rind flour produced by drying at 40 and $60^{\circ} \mathrm{C}$ respectively. RFD and YFD represent red and yellow-fleshed watermelon rind flour produced by drying in a freeze dryer respectively.

Presented data are mean values of three replications \pm standard deviation. 
Mean values in the same column with different superscript letters are significantly different ( $p$ $<0.05)$

The $\mathrm{a}_{\mathrm{w}}$ of all the flour samples produced by different drying treatments was averaged at 0.45 to 0.48 . For majority of the foods, the critical point below which no microorganism can grow is in the range of 0.6-0.7 [13]. Hence, all the flour samples can be deemed safe from microbial spoilage. No significant difference $(\mathrm{P}<0.05)$ were found between the water activity of flour samples made from air drying at $40^{\circ} \mathrm{C}$ and those of freeze dried (0.48-0.49), while a noticeable difference was observed for the drying at $60^{\circ} \mathrm{C}(0.45-0.47)$. Freeze drying involves the removal of water from a frozen product by a process called sublimation when a frozen liquid goes directly to the gaseous state without passing through the liquid phase. It is also clearly seen in that incremental increase in air drying temperature, $a_{w}$ decreases (Table 2). Similarly, in 20] also reported that the $\mathrm{a}_{\mathrm{w}}$ of dried banana decreases with increase in drying temperature. This might be due to the decrease in the moisture content of the flour sample with the increase in air drying temperature. As water is removed from the samples, mainly by evaporation in air dryer, at higher temperatures, the water evaporation rate is higher, influencing the moisture content and consequently $\mathrm{a}_{\mathrm{w}}$ of the samples. In [21] obtained similar results when they studied potato isotherms at temperatures of 30,45 and $60^{\circ} \mathrm{C}$ and found that $a_{w}$ decreased with reduction in moisture content. The $a_{w}$ of a food is however not the same thing as its moisture content. Although moist foods are likely to have greater $a_{w}$ than dry foods, this is not always so. A variety of foods may have exactly the same moisture content and yet have different $\mathrm{a}_{\mathrm{w}}$. The $\mathrm{a}_{\mathrm{w}}$ values of such foods depending upon the degree to which water is free or otherwise bound to food constituents, for example sugar.

\section{3. pH, Total Titratable Acidity (TTA) and Total Soluble Solid (TSS)}

Total titratable acidity (TTA) and $\mathrm{pH}$ are interrelated in terms of acidity, but have different impacts on food quality. However, the impact of acid on food flavour is much more determined by TTA than $\mathrm{pH}$ [22] since the $\mathrm{pH}$ of food gives an indication of its resistance to microbial attack [23]. The pH, total titratable acids (TTA) and total soluble solids (TSS) of all the watermelon rind flour samples prepared by different drying treatments are shown in Table 3. From the results obtained, it is clearly seen that all the TSS of the flour samples prepared 
by different drying treatments do not differ significantly $(\mathrm{P}>0.05)$ but in contrast, TTA and $\mathrm{pH}$ differ significantly $(\mathrm{P}<0.05)$.

Table 3. Effect of different drying conditions on the $\mathrm{pH}$, total titratable acidity and total soluble solid of watermelon rind flours

\begin{tabular}{cccc}
\hline Sample $^{1}$ & pH & TTA $^{2}$ (\% Acidity) & TSS $^{3}$ ( ${ }^{\circ}$ Brix $)$ \\
\hline R40 & $5.29^{\mathrm{c}} \pm 0.01$ & $0.13^{\mathrm{a}} \pm 0.00$ & $2.43^{\mathrm{a}} \pm 0.06$ \\
R60 & $5.26^{\mathrm{b}} \pm 0.01$ & $0.15^{\mathrm{b}} \pm 0.00$ & $2.30^{\mathrm{a}} \pm 0.10$ \\
RFD & $4.71^{\mathrm{a}} \pm 0.01$ & $0.17^{\mathrm{c}} \pm 0.00$ & $2.37^{\mathrm{a}} \pm 0.06$ \\
Y40 & $5.53^{\mathrm{c}} \pm 0.02$ & $0.16^{\mathrm{a}} \pm 0.00$ & $2.43^{\mathrm{a}} \pm 0.06$ \\
Y60 & $5.31^{\mathrm{b}} \pm 0.01$ & $0.18^{\mathrm{b}} \pm 0.00$ & $2.40^{\mathrm{a}} \pm 0.10$ \\
YFD & $4.66^{\mathrm{a}} \pm 0.01$ & $0.23^{\mathrm{c}} \pm 0.01$ & $2.50^{\mathrm{a}} \pm 0.00$ \\
\hline
\end{tabular}

${ }^{1} \mathrm{R} 40$ and $\mathrm{R} 60$ represent red-fleshed watermelon rind flour produced by drying at 40 and $60^{\circ} \mathrm{C}$ respectively. Y40 and Y60 represent yellow-fleshed watermelon rind flour produced by drying at 40 and $60^{\circ} \mathrm{C}$ respectively. RFD and YFD represent red and yellow-fleshed watermelon rind flour respectively produced by drying in a freeze dryer.

${ }^{2}$ TTA represents total titratable acids

${ }^{3}$ TSS represents total soluble solids

Presented data are mean values of three replications \pm standard deviation.

Mean values in the same column with different superscript letters are significantly different ( $p$ $<0.05)$.

The decrease in moisture content in the fruits is usually accompanied by an increased percentage of TSS, since TSS is the major component of dry matter [24]. Thus, the value of TSS will always increase significantly after drying. Results from determination of TSS of flour samples show no significant difference $(\mathrm{P}>0.05)$ in the TSS value between the three different drying treatments $\left(2.30-2.43{ }^{\circ}\right.$ Brix for red variety; $2.40-2.50{ }^{\circ}$ Brix for yellow variety). Similarly, in [25] also reported that there was no significant difference in the TSS value of the dried tomato samples between the three levels of drying temperature $(55,65$ and $\left.75^{\circ} \mathrm{C}\right)$ 
Comparing the results between the different drying treatments, freeze dried sample had higher value for TTA $(0.17 \%$ for red variety; $0.23 \%$ for yellow variety), followed by hot-air oven drying at $60^{\circ} \mathrm{C}\left(0.15 \%\right.$ for red variety; $0.18 \%$ for yellow variety) and $40^{\circ} \mathrm{C}(0.13 \%$ for red variety; $0.16 \%$ for yellow variety). In [26] also reported that the freeze drying method resulted in a significantly higher titratable acidity than the hot-air oven drying, in mango kernel and peel powder. It is due to the nature of the freeze drying method, carried out at a relatively low temperature which able to preserve the organic acid presence in the fruits and thereby resulting in a significantly higher TTA value. Similarly, in [27] also pointed out that more organic acids may occur in the lyophilizates than in the thermally dried material. Results from determining acidity of air dried flour samples indicated that by increasing dryer air temperature, TTA increased. However, the $\mathrm{pH}$ showed a decreasing trend. This result is in agreement with several previous studies $[6,17,25,28]$, whereby the rise of drying temperature is accompanied by the decrease in $\mathrm{pH}$ and increase in acidity. According to [28], the increase in TTA with drying temperature may be due to the organic acids becoming more concentrated while the reduction in $\mathrm{pH}$ with drying temperature may be due to increased dissociation of the organic acids with temperature.

\subsection{Bulk Density, Water Absorption Capacity (WAC) and Oil Absorption Capacity (OAC)}

The bulk density, water absorption capacities (WAC) and oil absorption capacities (OAC) of all the watermelon rind flour samples prepared by different drying treatments is presented in Table 4. 
Table 4. Effect of different drying conditions on the bulk density, water absorption capacity and oil absorption capacity of watermelon rind flours

\begin{tabular}{cccc}
\hline Sample $^{1}$ & Bulk Density (g/ mL) & WAC $^{2}(\mathbf{g}$ Water/ g) & OAC $^{3}(\mathbf{g ~ O i l} / \mathbf{g})$ \\
\hline R40 & $0.36^{\mathrm{c}} \pm 0.07$ & $10.57^{\mathrm{b}} \pm 0.05$ & $3.42^{\mathrm{c}} \pm 0.11$ \\
$\mathrm{R} 60$ & $0.34^{\mathrm{b}} \pm 0.02$ & $11.04^{\mathrm{c}} \pm 0.17$ & $3.27^{\mathrm{b}} \pm 0.03$ \\
$\mathrm{RFD}$ & $0.09^{\mathrm{a}} \pm 0.01$ & $7.36^{\mathrm{a}} \pm 0.14$ & $3.08^{\mathrm{a}} \pm 0.02$ \\
Y40 & $0.38^{\mathrm{c}} \pm 0.04$ & $8.78^{\mathrm{b}} \pm 0.08$ & $3.44^{\mathrm{c}} \pm 0.04$ \\
Y60 & $0.33^{\mathrm{b}} \pm 0.03$ & $10.92^{\mathrm{c}} \pm 0.08$ & $2.69^{\mathrm{b}} \pm 0.06$ \\
YFD & $0.10^{\mathrm{a}} \pm 0.04$ & $5.92^{\mathrm{a}} \pm 0.09$ & $2.32^{\mathrm{a}} \pm 0.05$
\end{tabular}

${ }^{1} \mathrm{R} 40$ and $\mathrm{R} 60$ represent red-fleshed watermelon rind flour produced by drying at 40 and $60^{\circ} \mathrm{C}$ respectively. Y40 and Y60 represent yellow-fleshed watermelon rind flour produced by drying at 40 and $60^{\circ} \mathrm{C}$ respectively. RFD and YFD represent red and yellow-fleshed watermelon rind flour produced by drying in a freeze dryer respectively.

${ }^{2} \mathrm{WAC}$ represents water adsorption capacity

${ }^{3} \mathrm{OAC}$ represents oil adsorption capacity

Presented data are mean values of three replications \pm standard deviation.

Mean values in the same column with different superscript letters are significantly different ( $p$ $<0.05)$

From the results obtained, it is shown that all the assessed functional properties of the watermelon rind flour samples differed significantly $(\mathrm{P}<0.05)$ from one another. Comparing the different drying treatments, freeze drying method had the lowest value obtained for bulk density $(0.09 \mathrm{~g} / \mathrm{mL}$ for red variety; $0.10 \mathrm{~g} / \mathrm{mL}$ for yellow variety). Conversely, the bulk densities of flours made from air drying method were significantly higher $(\mathrm{P}<0.05)$ $(0.34-0.36 \mathrm{~g} / \mathrm{mL}$ for red variety; $0.33-0.38 \mathrm{~g} / \mathrm{mL}$ for yellow variety). High bulk density is desirable for reducing shipping and packaging costs as it implied that lesser packaging material would be required, as bulk density gives an indication of the relative volume of packaging material required [29]. The results obtained in this research resembled a mirror image of the study conducted by [14], whereby bulk density of the hot-air oven dried banana flour was significantly higher than that of the freeze dried. This might be attributed to the 
higher porosity of the freeze dried flour. When comparing with hot-air oven drying at 40 to $60^{\circ} \mathrm{C}$, the bulk density value of flour samples hot-air oven dried at $40^{\circ} \mathrm{C}$ was found to be the highest $(0.36 \mathrm{~g} / \mathrm{mL}$ for red variety; $0.38 \mathrm{~g} / \mathrm{mL}$ for yellow variety) whilst the lowest corresponds to the flour samples made from air drying at $60^{\circ} \mathrm{C}(0.34 \mathrm{~g} / \mathrm{mL}$ for red variety; 0.33 $\mathrm{g} / \mathrm{mL}$ for yellow variety). This observation has been in accordance with earlier study conducted by who demonstrated that the cocoyam flour sample dried at $50^{\circ} \mathrm{C}$ had the highest bulk density value, inversely, sample dried at $85^{\circ} \mathrm{C}$ had the lowest value. This was due to the decrease in the moisture content of the flour samples with the increase in drying temperatures. It noted that bulk density of a food sample is related with its moisture content.

The water absorption capacity (WAC) indicates the mass of the water uptake per unit mass of dried powder. Comparing hot-air oven drying to freeze drying method, WAC of air dried flours (10.57-11.04 $\mathrm{g}$ of water/g of sample for red variety; 8.78-10.92 $\mathrm{g}$ of water/g of sample for yellow variety) was significantly higher $(\mathrm{P}<0.05)$ than that of freeze dried $(7.36 \mathrm{~g}$ of water $/ \mathrm{g}$ of sample for red variety; $5.92 \mathrm{~g}$ of water/g of sample for yellow variety). Similarly, in [14] also reported that the WAC of the freeze dried green banana flour was found to be lower than that of hot-air dried flour. Results from determining WAC of flour samples dried by using hot-air oven dryer at temperatures of 40 and $60^{\circ} \mathrm{C}$ indicated that an increase in air dryer temperature, the WAC increases. The same observation has been reported by [30], whereby the WAC of the apple pomace powder increases when the tray dryer temperature increased from 60 to $80^{\circ} \mathrm{C}$. This was attributed to the increase in drying temperature and hydrophilic tendency of the starch increased alongside. In [31] reported that at higher temperature, starch expands rapidly especially in the amorphous region. Expansion of the starch enables more water to be absorbed in the amorphous space of starch, which leads to a swelling phenomenon. Flours with high WAC find useful applications as functional ingredients in bakery products as this could prevent staling by reducing moisture loss [32]. WAC is also important in the development of ready-to-eat foods and a high absorption capacity may assure product cohesiveness as reported by [33]. The result obtained shows that the hot-air oven dried watermelon rind flours; red and yellow-fleshed variety has a good ability to bind water. This result suggests that they could be used in the bakery industry. 
Comparing the different drying treatments, the hot-air oven drying method had the higher value obtained for the oil absorption capacity (OAC) (3.27-3.42 g of oil/g of sample for red variety; 2.69-3.44 $\mathrm{g}$ of oil/g of sample for yellow variety), while the lowest value was corresponded with freeze dried flour (3.08 $\mathrm{g}$ of oil/g of sample for red variety; $2.32 \mathrm{~g}$ of oil/g of sample for yellow variety). The same observation has been reported by [14], whereby that the OAC of hot-air oven dried green banana flour was higher than that of freeze dried. The results obtained in this study are however, in contrast with the study by [26], whereby it is reported that the freeze dried mango kernel powder had the highest OAC values whereas the hot-air oven drying dried had lower values. The disparities observed could be attributed to the method used as well as the varietal differences. Comparing the results from determining the OAC of flour samples dried by using hot-air oven dryer at temperatures of 40 and $60^{\circ} \mathrm{C}$, it is clearly seen that an increase in air dryer temperature leads to the decrease in OAC. Proteins influence the OAC of food matrices, with increased non-polar amino acid residues enhancing hydrophobicity and fat binding through capillary action. In [34] reported that thermal treatment slightly decreased the OAC of heat treated samples, possibly due to the unfolding of proteins when exposed to heat, thereby decreasing the surface hydrophobicity of the proteins. The effect is more prevalence at high temperature as observed in the present study, resulting in a significantly lower OAC value of flours produced by air drying at $60^{\circ} \mathrm{C}$. Hydrophobic proteins have higher preference for binding to lipids [35]. The absorption of oil by protein surfaces increases the hydrophobic interaction of proteins with flavour compounds as well as the binding of food to the inner walls of the mouth during mastication. Thus, OAC of food determines the mouth-feel, flavour retention as well as shelf stability of baked or fried foods and meat products especially [36].

\subsection{Total Sugar, Total Starch, Resistant Starch and Digestible Starch}

The total sugar, total starch, resistant starch, and digestible starch of all the watermelon rind flour samples prepared by different drying conditions are depicted in Fig. 1 (A), (B), (C) and (D) respectively. Freeze drying methods had the highest value obtained for total sugar content (30.12\% for red variety; $55.72 \%$ for yellow variety), followed by hot-air drying at $60^{\circ} \mathrm{C}(25.91 \%$ 
for red variety; $49.67 \%$ for yellow variety) and $40^{\circ} \mathrm{C}(21.20 \%$ for red variety; $31.13 \%$ for yellow variety) (Fig. 1 (A)).

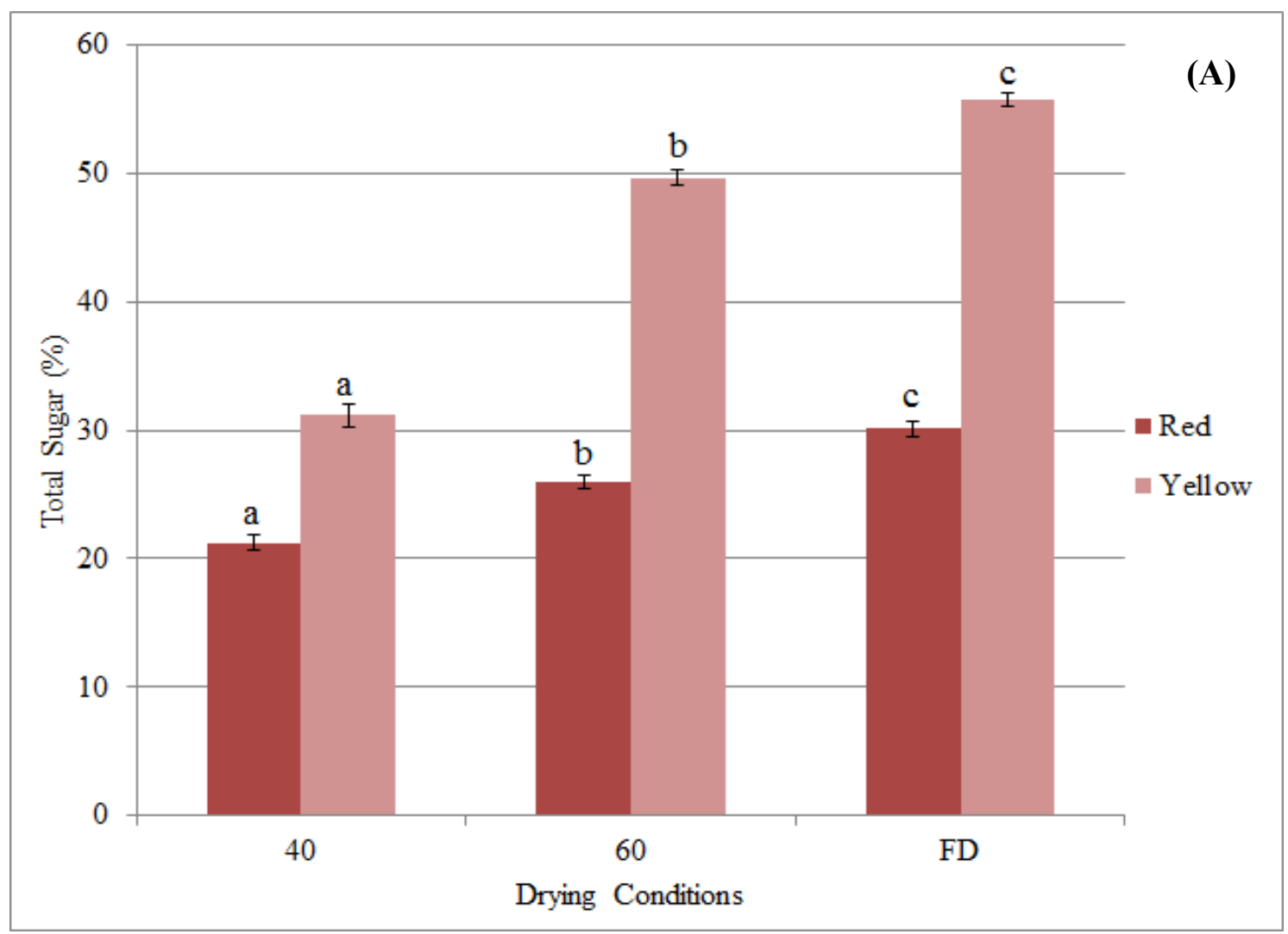

Fig.1. (A) Effect of different drying conditions on total sugar of watermelon rind flours.

Error bars indicate the mean values of three replications \pm standard deviation. Different letters on top of each same colour bar indicate significant different $(\mathrm{P}<0.05)$ from other bars

The total sugar of flour treated with hot-air drying and freeze-drying was observed similar to those found in the present work. In [37] pointed out that the freeze drying originated products with less reduction in sugars as compared to that of hot-air oven drying. From the result obtained, it is also apparent that the total sugar content increased with an increase in drying temperature. This is in-line with that finding reported by [38]. This trend can be partially explained by a higher degree of starch damage and the fact that both amylose and amylopectin can be hydrolyzed by amylolitic enzymes, which produces an increment in the amount of depleted sugars as glucose [39]. However, the relationship between starch and sugar content is not clear and difficult to establish because several factors influence the enzymatic process, such as presence of damaged starch, crystalline structure and amylose/amylopectin ratio, as well as other non-enzymatic processes can be simultaneously developed [39]. Contrary to this, 
in [37] stated that the total sugar content decreased with increasing drying temperature. They also concluded that the higher losses were corresponding to treatments with the higher temperature $\left(60^{\circ} \mathrm{C}\right)$ and more thermal degradation.

Fig. 1 (B) indicates that drying treatments as well as drying temperature had exert a marked effect on the total starch content. Based on the findings of this study, the starch content of the freeze dried flour was found to be significantly higher $(\mathrm{P}<0.05)(4.72 \%$ for red variety; 5.45\% for yellow variety) and the lowest total starch corresponds to the flour made from hot-air oven drying at higher temperature, i.e. $60^{\circ} \mathrm{C}(3.28 \%$ for red variety; $4.24 \%$ for yellow variety). The results obtained from the present study also show that the starch content decreases with the increase in the drying temperature. This finding could be explained by the degradation of starch by amylases during hot-air oven drying [40] and this is more evident for drying temperatures at $60^{\circ} \mathrm{C}$, corresponding to the enzymatic optimum temperatures [12].

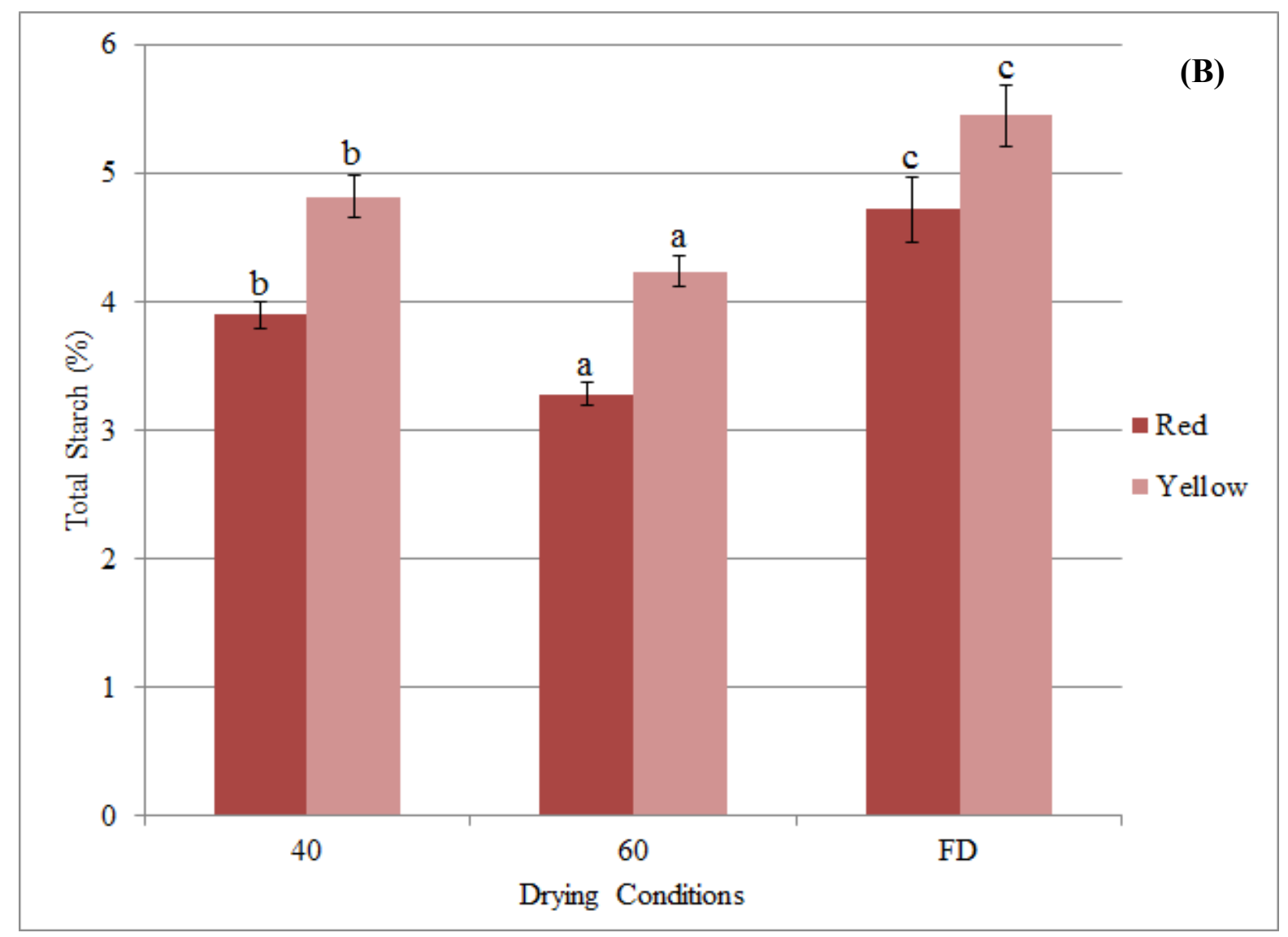

Fig.1. (B) Effect of different drying conditions on total starch of watermelon rind flours 
Error bars indicate the mean values of three replications \pm standard deviation. Different letters on top of each same colour bar indicate significant different $(\mathrm{p}<0.05)$ from other bars

Fig. 1 (C) demonstrated that the resistant starch content of the freeze dried flour was found to be the lowest (2.24\% for red variety; $2.38 \%$ for yellow variety). The highest resistant starch content was associated with flour prepared by drying at a $60^{\circ} \mathrm{C}(2.42 \%$ for red variety; $2.68 \%$ for yellow variety) and it dropped significantly $(\mathrm{P}<0.05)$ with decreasing drying temperature. Similarly, in [41] also show that the resistant starch of acorn flours increased with drying temperature up to $60^{\circ} \mathrm{C}$. In [42] mentioned that the major commercial source of resistant starch is that of high amylose starch and resistant starch increased by heating process. In the studies of [43-44], the thermal processing induces an increase in resistant starch values mainly due to amylose retrogradation. According to [42], type III resistant starch comprises retrograded starch and can be found in the food samples that undergone heating process. Therefore, it is assumed that, type III resistant starch (retrograded starch) was present in the watermelon rind flour prepared by hot-air drying at $60^{\circ} \mathrm{C}$. The resistant starch content present in freeze dried flour however, is found to be the lowest among all the drying condition tested. This event might be attributed to the watermelon rind was frozen and the sample temperature decreased to $-20^{\circ} \mathrm{C}$ within a short period of time. Under such conditions, it is expected that the mobility of gelatinized starch or arrangement of the gelatinized starch molecules to a more ordered structure did not occur or in a lesser amount [45]. 


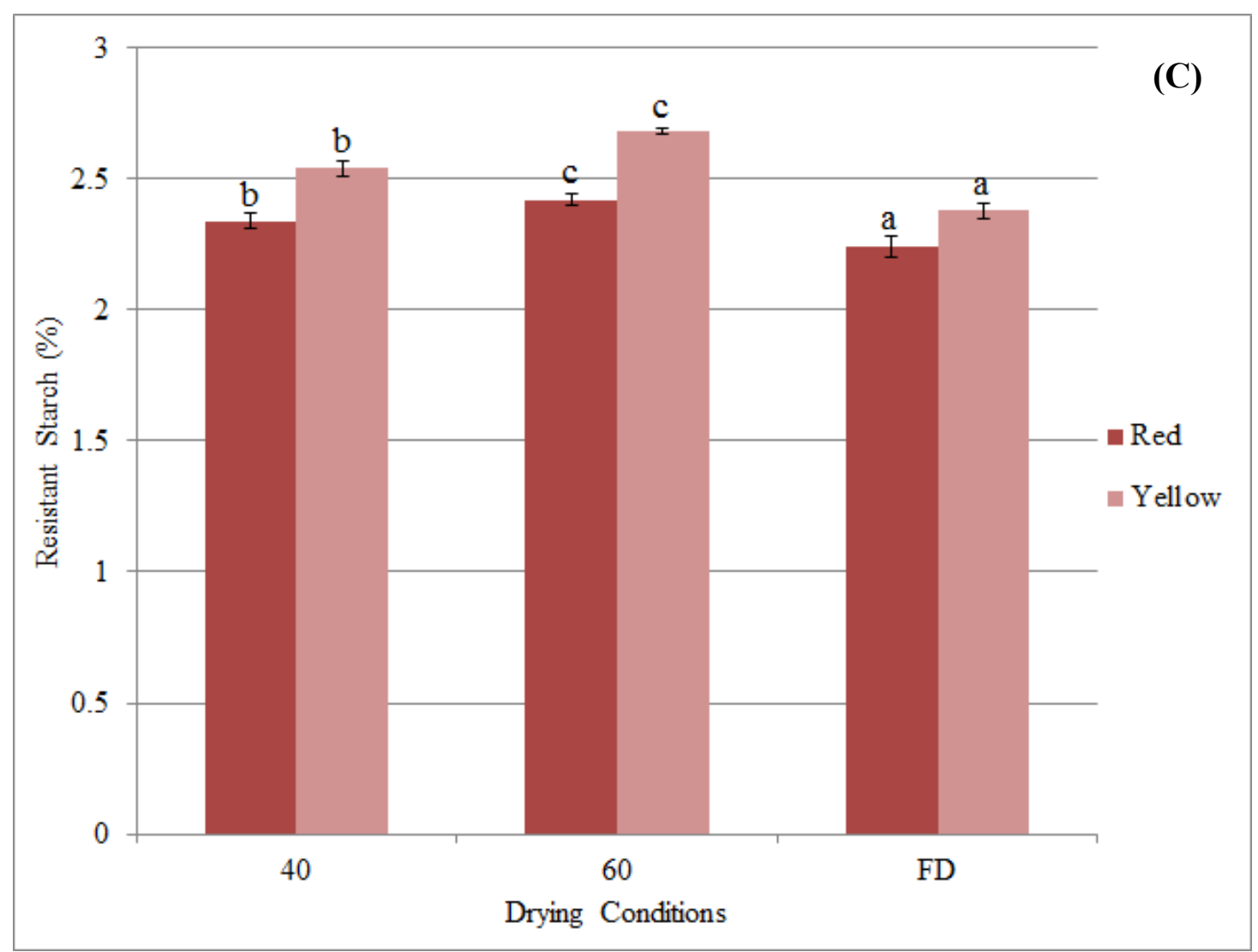

Fig.1. (C) Effect of different drying conditions on resistant starch of watermelon rind flours. Error bars indicate the mean values of three replications \pm standard deviation. Different letters on top of each same colour bar indicate significant different $(p<0.05)$ from other bars. In general, a noticeable difference was observed between the digestible starch content of all the watermelon rind flour samples prepared by different drying treatments (Fig. 1D). The digestible starch content of the freeze dried flour was significantly higher $(\mathrm{P}<0.05)(2.48 \%$ for red variety; $3.07 \%$ for yellow variety) than those produced by the air drying methods (0.86-1.56\% for red variety; $1.57-2.28 \%$ for yellow variety). It is also apparent that incremental increase in hot-air drying temperature, digestible starch content decreases. This event could be attributed to the lower resistant starch content of the freeze dried flour and flour made from air drying at $40^{\circ} \mathrm{C}$. The overall results obtained showed that good quality flour in terms of total amount of sugar, starch and digestible starch can be produced by utilising the freeze drying treatment method. However, freeze dried flour contains a low amount of resistant starch compared to flour made using the hot-air oven drying process. 


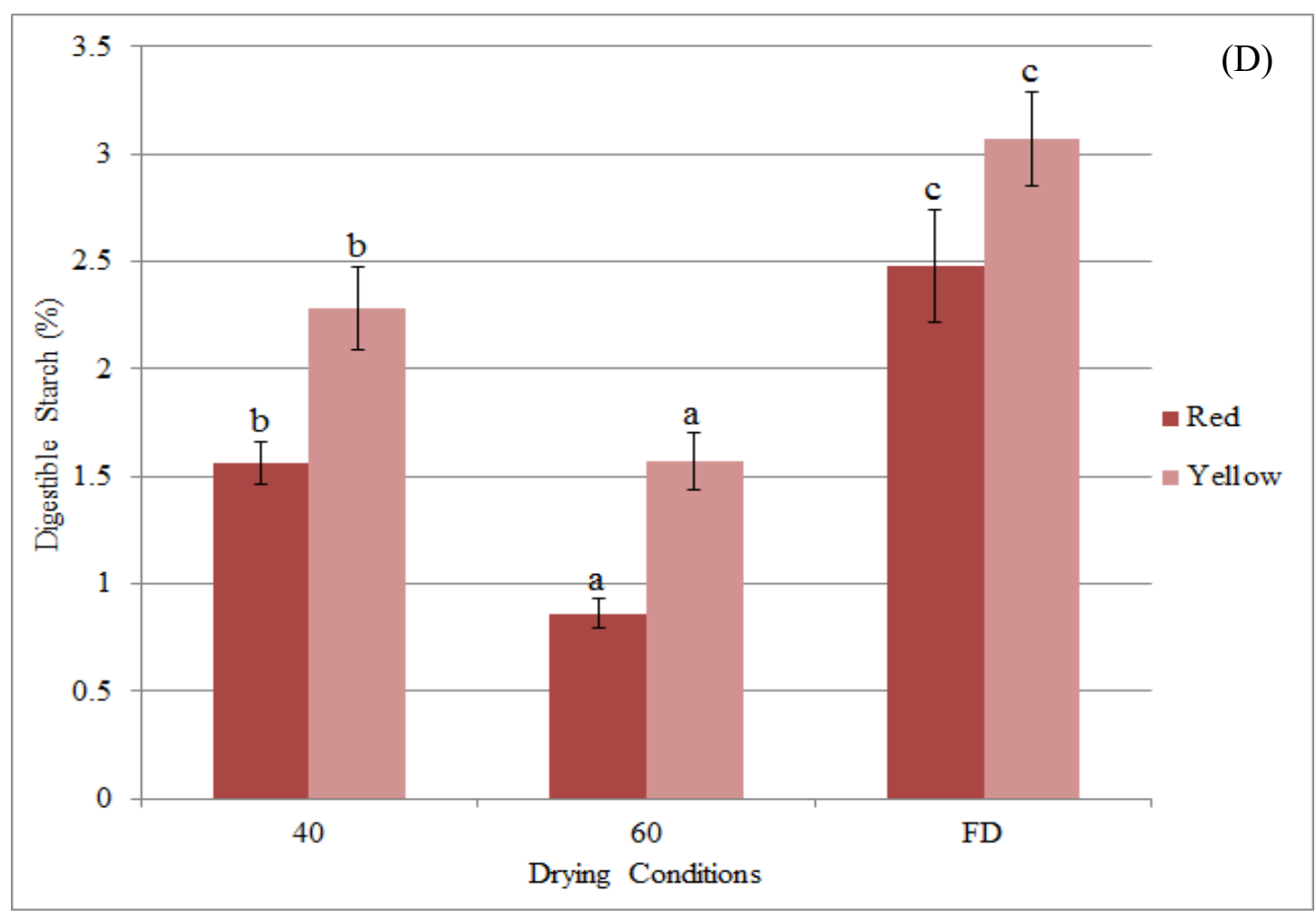

Fig.1. (D) Effect of different drying conditions on digestible starch of watermelon rind flours Error bars indicate the mean values of three replications \pm standard deviation. Different letters on top of each same colour bar indicate significant different $(p<0.05)$ from other bars.

\section{EXPERIMENTAL}

\subsection{Materials}

Watermelon (Citrullus lanatus) samples (both red and yellow variety) were obtained from commercial growers in Tembila, Besut, Terengganu, in October 2015. The watermelons were selected according to the guidelines as described by [46] whereby the characteristics of ripe watermelons should include the yellowish-cream ground spot, shining skin, dispersed stripes and producing hollow sound when flicked. All the chemicals used in this study were of analytical grade.

\subsection{Watermelon Rind Flour Preparation}

The watermelon samples were washed and the flesh, rind, and peel were separated. The peeled melons were cut transversely between the bloom and stem ends. Cut watermelon samples were sliced to obtain the rind (white area part). The rind samples were sliced into 
uniform pieces using industrial fruit slicer (Santos Vegetable slicer 48, Lyon, France), and then dried in laboratory dryers (Tech-Lab, FDD-720, Selangor, Malaysia) for overnight. Drying temperature was set by the built-in dial thermostat and maintained at temperature of 40 or $60^{\circ} \mathrm{C}$ for the preparation of both red and yellow variety watermelon rind flour produced by drying at 40 and $60^{\circ} \mathrm{C}$ respectively ( $\mathrm{R} 40$ and Y40 are the abbreviations for red and yellow-fleshed watermelon rind flour produced by drying at $40^{\circ} \mathrm{C}$ respectively; R60 and Y60 are the abbreviations for red and yellow-fleshed watermelon rind flour produced by drying at $60^{\circ} \mathrm{C}$ respectively).

To prepare freeze dried watermelon rind flour (RFD and YFD are the abbreviations for red and yellow-fleshed watermelon rind flour produced by drying in a freeze dryer respectively), the watermelon rind samples were frozen overnight at $-18^{\circ} \mathrm{C}$ and lyophilized in a freeze dryer (SP Scientific, 25 L Genesis SQ Super ES-55 Pilot, Pennsylvania, USA) for 2 days. The dried watermelon rind samples were ground using a laboratory mill and sieved into fine powder by using mechanical sieve shaker $(250 \mu \mathrm{m})$. All samples were kept in an airtight plastic container and stored in chiller prior to analysis.

\subsection{Colour Measurement}

Colour measurement of the flour sample was done in terms of the Commission Internationale de L'Eclairage (CIE) $L^{*} a^{*} b^{*}$ scale where $L^{*}$ represents the degree of lightness $\left(0^{\circ}=\right.$ black, $100^{\circ}=$ white $), a^{*}$ denotes the red/green value $(+$ value $=$ redness, - value $=$ greenness $)$ and $\mathrm{b}^{*}$ represents the yellow/blue value $(+$ value $=$ yellowness, - value $=$ blueness $)$. The colourimeter (Konica Minolta, CR-400/410, Tokyo, Japan) was calibrated with white calibration tiles provided with the instrument prior to analysis.

\subsection{Water Activity $\left(a_{w}\right)$ Measurement}

Water activity $\left(\mathrm{a}_{\mathrm{w}}\right)$ of the flour sample was measured by using water activity meter (Decagon's AquaLab Series 3, Pullman, USA) at $25^{\circ}$ C. Samples (about 2 g) were evenly placed into plastic cells and were allowed to equilibrium within the headspace of the sealed chamber. The reading was then recorded when equilibrium was achieved [19]. 


\section{5. pH Measurement}

A benchtop pH meter (Thermo Scientific Orion 3-Star, Massachusetts, USA) was calibrated with standard buffer solution of $\mathrm{pH} 4.0,7.0$ and 10.0. Flour sample $(0.5 \mathrm{~g})$ was weighed into a $100 \mathrm{~mL}$ beaker and $10 \mathrm{~mL}$ of distilled water was added to obtain slurry. The $\mathrm{pH}$ was then measured by inserting directly the electrode that had been pre-rinsed with distilled water into $10 \mathrm{~mL}$ of slurry in a beaker. The $\mathrm{pH}$ electrode was allowed to stabilize before recording.

\subsection{Total Titratable Acidity Analysis}

Total titratable acidity of the flour sample was determined according to the method as described by Bainbridge et al [47] with slight modifications. Flour sample (0.5 g) was weighed into a $100 \mathrm{~mL}$ beaker and $10 \mathrm{~mL}$ of distilled water was added to obtain slurry. The slurry was then added with 5 drops of phenolphthalein indicator and titrated against $0.1 \mathrm{~N}$ sodium hydroxide $(\mathrm{NaOH})$ solution until the mixture turns pink. The titre volume was recorded and the total titratable acidity in the sample was expressed as percentage of malic acid (acid factor used: 0.067).

\subsection{Total Soluble Solid Measurement}

Flour sample $(0.5 \mathrm{~g})$ was diluted with $10 \mathrm{~mL}$ of distilled water and the total soluble solids content was determined using refractometer (measurement range of 0-2 ${ }^{\circ} \mathrm{Brix}$ ) (ATAGO, MASTER-50H, Tokyo, Japan) that come with an automatic temperature compensation function. The result was expressed as ${ }^{\circ}$ Brix.

\subsection{Bulk Density Measurement}

Bulk density of the flour sample was determined using the method of [48]. A graduated cylinder tubes were weighed and flour sample filled to $5 \mathrm{~mL}$ by constant tapping until there was no further change in volume. The contents were weighed and the difference in weight was determined. The bulk density was expressed as gram per $\mathrm{mL}$ of the sample $(\mathrm{g} / \mathrm{mL})$.

\subsection{Total Sugar Determination}

Total sugar content of the flour sample was evaluated based on phenol sulphuric acid method as described by [49] with slight modifications. Flour sample $(50 \mathrm{mg})$ was extracted with $80 \%$ ethanol $(5 \mathrm{~mL})$ and then boiled in a water bath at $95^{\circ} \mathrm{C}$ for $10 \mathrm{~min}$. The extraction process was repeated for three times. After each extraction, the tube was centrifuged at 2,500 rpm for 5 
min and the supernatants of the three extractions were combined for sugar analysis. To 0.5 $\mathrm{mL}$ of the ethanol extract, $1 \mathrm{~mL}$ of $2 \%$ phenol solution and $2 \mathrm{~mL}$ of concentrated sulphuric acid $\left(\mathrm{H}_{2} \mathrm{SO}_{4}\right)$ were added. The capped tubes were then incubated in a water bath at $22^{\circ} \mathrm{C}$ for $30 \mathrm{~min}$. The absorbance of the sample was read at $490 \mathrm{~nm}$ using a UV-VIS spectrophotometer (Shimadzu, UV mini-1240, Kyoto, Japan). The amount of sugars was determined by reference to a standard curve prepared with working standards containing up to $100 \mathrm{mg} / \mathrm{L}$ of D-glucose.

\subsection{Total Starch Determination}

Total starch in the sample was determined according to the method as described by [50]. Flour sample $(50 \mathrm{mg})$ was added with $6 \mathrm{~mL}$ of $2 \mathrm{M}$ potassium hydroxide $(\mathrm{KOH})$ and then incubated in a shaking water bath at $27^{\circ} \mathrm{C}$ for $30 \mathrm{~min}$. After this, $3 \mathrm{~mL}$ of $0.4 \mathrm{M}$ sodium acetate buffer ( $\mathrm{pH} 4.75$ ) and $60 \mu \mathrm{L}$ of amyloglucosidase were added to the suspension and then further incubated for $45 \mathrm{~min}$ at $60^{\circ} \mathrm{C}$. A standard curve of glucose solution was prepared. The absorbance of the sample was read against a reagent blank (glucose oxidase/peroxidase reagent) at $500 \mathrm{~nm}$. Total starch was calculated as $\mathrm{mg}$ of glucose $\times 0.9$ (conversion factor).

\subsection{Resistant Starch and Digestible Starch Determination}

Resistant starch was determined according to the direct method as described by [51]. In brief, $100 \mathrm{mg}$ of sample was added with $10 \mathrm{~mL}$ of potassium chloride-hydrochloric acid (KCl-HCl) buffer ( $\mathrm{pH} \mathrm{1.5)}$ and $0.2 \mathrm{~mL}$ of pepsin solution. The mixture was then incubated in a water bath (at $40^{\circ} \mathrm{C}$ for $60 \mathrm{~min}$ ), followed by the addition of $9 \mathrm{~mL}$ of $0.1 \mathrm{M}$ Tris-maleate buffer ( $\mathrm{pH}$ 6.9) and $1 \mathrm{~mL}$ of $\alpha$-amylase. The mixture was further incubated for $16 \mathrm{~h}$ in a water bath at $37^{\circ} \mathrm{C}$. Followed by this, the sample was washed twice with distilled water and $3 \mathrm{~mL}$ of distilled water was added to the obtained residue. To this, $3 \mathrm{~mL}$ of $4 \mathrm{M} \mathrm{KOH}$ was added and incubated for $30 \mathrm{~min}$ at room temperature with constant shaking. Approximately $5.5 \mathrm{~mL}$ of 2 $\mathrm{M} \mathrm{HCl}, 3 \mathrm{~mL}$ of $0.4 \mathrm{M}$ sodium acetate buffer $(\mathrm{pH} 4.75)$ and $80 \mu \mathrm{L}$ of amyloglucosidase were added into the mixture. This mixture was then placed in a water bath at $60^{\circ} \mathrm{C}$ for $45 \mathrm{~min}$. A standard curve of glucose solution was used. The absorbance of the sample was read against a reagent blank (glucose oxidase/peroxidase reagent) at $500 \mathrm{~nm}$. Resistant starch was calculated 
as $\mathrm{mg}$ of glucose $\times 0.9$ (conversion factor). The digestible starch of the samples was obtained by calculation (Digestible starch $=$ Total starch-Resistant starch) [50].

\subsection{Functional Properties}

Water absorption capacity (WAC) and oil absorption capacity (OAC) of flour sample were determined in accordance to [52], but with slight modifications. Flour sample (0.5 g) was weighed into a $50 \mathrm{~mL}$ graduated conical centrifuge tubes and about $10 \mathrm{~mL}$ of water (for WAC analysis) or refined vegetable oil (for OAC analysis) was added. The suspensions were allowed to stand at room temperature $\left(30 \pm 2^{\circ} \mathrm{C}\right)$ for about $1 \mathrm{~h}$ and then centrifuged at 4,000 rpm for $30 \mathrm{~min}$. The supernatant was then decanted and discarded. The weight of water or oil absorbed by the flour sample was calculated and expressed as grams of water or oil absorption based on the original sample weight, i.e. $g$ of water/g of sample and $g$ of oil/g of sample respectively.

\subsection{Statistical Analysis}

Statistical analyses were conducted using Statistical Package for the Social Sciences version 17.0 software. The results obtained from the present study are represented as the mean values of three individual replicates \pm the standard deviation (S.D.). Significant differences between the mean values were determined using Duncan's multiple range tests at a significance level of $\mathrm{P}<0.05$.

\section{CONCLUSION}

Different drying conditions had a significant effect $(\mathrm{P}<0.05)$ on the physicochemical and functional properties of the watermelon rind flour, except for total soluble solid content. In a comparison of hot-air oven drying and freeze drying processes, the latter resulted in flour with better quality in terms of colour parameters, $\mathrm{pH}$, total titratable acidity, total sugar, total starch and digestible starch. However, freeze dried flour had significantly lower amount of resistant starch when compared to those of hot-air dried flour samples. When the amount of resistant starch present is not a critical factor in the end product, freeze drying may be considered the best method to be utilized for the production of watermelon rind flour. In contrary, when high resistant starch end products are of interest, hot-air oven drying at $60^{\circ} \mathrm{C}$ would be the suitable 
drying method. Although freeze drying produced watermelon rind flour with better quality, however flour produce through hot-air oven drying at $60^{\circ} \mathrm{C}$ is more economical. With their relatively lower $\mathrm{a}_{\mathrm{w}}$ and $\mathrm{pH}$ values, these watermelon rind flours are expected to have a long shelf life. Reduction in packaging and transportation cost due to their low bulk density value also makes hot-air oven drying at $60^{\circ} \mathrm{C}$ to be more economical, hence lowering the cost of the end product.

\section{ACKNOWLEDGMENTS}

The authors wish to thank Universiti Sultan Zainal Abidin for the financial support from the University Research Grant [UNISZA/2015/DPU/(2)].

\section{REFERENCES}

[1] Perkins-Veazie P, Collins J K. Flesh quality and lycopene stability of fresh-cut watermelon. Postharvest Biology and Technology, 2004, 31(2):159-166

[2] Souad A M, Jamal P, Olorunnisola K S. Effective jam preparations from watermelon waste. International Food Research Journal, 2012, 19(4):1545-1549

[3] Hoque M M, Iqbal A. Drying of watermelon rind and development of cakes from rind powder. International Journal of Novel Research in Life Sciences, 2015, 2(1):14-21

[4] Ho L H, Dahri N C. Effect of watermelon rind powder on physicochemical, textural, and sensory properties of wet yellow noodles. CyTA-Journal of Food, 2016, 14(3):465-472

[5] Athmaselvi K A, Alagusundaram K, Kavitha C V, Arumuganathan T. Impact of pre-treatment on colour and texture of watermelon rind. International Agrophysics, 2012, 26(3):235-242

[6] Purkayastha M D, Nath A, Deka B C, Mahanta C L. Thin layer drying of tomato slices. Journal of Food Science and Technology, 2013, 50(4):642-653

[7] Fan L, Li J, Deng K, Ai L. Effects of drying methods on the antioxidant activities of polysaccharides extracted from Ganoderma lucidum. Carbohydrate Polymers, 2012, 87(2):1849-1854 
[8] Tsami E, Krokida M K, Drouzas A E. Effect of drying method on the sorption characteristics of model fruit powders. Journal of Food Engineering, 1998, 38(4):381-392

[9] Ahmed J, Al-Attar H. Effect of drying method on rheological, thermal, and structural properties of chestnut flour doughs. Food Hydrocolloids, 2014, 51:76-87

[10] Argyropoulos D, Heindl A, Muller J. Evaluation of processing parameters for hot-air drying to obtain high quality dried mushrooms in the Mediterranean region. In Conference on International Research on Food Security, Natural Resource Management and Rural Development, 2008, pp. 7-9

[11] Araujo M G F, Bauab T M. Chapter 4: Microbial quality of medicinal plant materials. In I. Akyar (Ed.), Latest research into quality control. Rijeka: IN TECH, 2012, pp. 67-81

[12] Correia P, Leitão A, Beirão-da-Costa M L. The effect of drying temperatures on morphological and chemical properties of dried chestnuts flours. Journal of Food Engineering, 2009, 90(3):325-332

[13] Bonazzi C, Dumoulin, E. Quality changes in food materials as influenced by drying processes. In E. Tsotsas, \& A. S. Mujumdar (Eds.), Modern drying technology-volume 3: Product quality and formulation. Weinheim: Wiley-VCH Verlag GmbH and Co. KGaA, 2011, pp. $1-20$

[14] Asif-Ul-Alam S M, Islam M Z, Hoque M M, Monalisa K. Effects of drying on the physicochemical and functional properties of green banana (Musa sapientum) flour and development of baked product. American Journal of Food Science and Technology, 2014, 2(4):128-133

[15] Ajala A S, Babarinde G O, Olatunde S J. Evaluation of drying temperature on proximate, thermal and physical properties of cocoyam flour. Global Journal of Engineering, Design and Technology, 2014, 3(4):13-18

[16] Sacilik K, Elicin A K. The thin layer drying characteristics of organic apple slices. Journal of Food Engineering, 2006, 73(3):281-289

[17] Nikjooy S, Jahanshahi S S. Effect of hot-air drying conditions on the quality of rhubarb (Rheum Ribes L.). International Journal of Agriculture and Crop Sciences, 2014, 7(5):230-236 
[18] Que F, Mao L, Fang X, Wu T. Comparison of hot air-drying and freeze-drying on the physicochemical properties and antioxidant activities of pumpkin (Cucurbita moschata Duch.) flours. International Journal of Food Science and Technology, 2008, 43(7):1195-1201

[19] Decagon Devices. AquaLab water activity meter: Operator's manual for series 4, 4TE, 4TEV, DUO and TEV DUO. Washington DC: Decagon Devices Inc., 2016

[20] Cano-Chauca M, Ramos A M, Stringheta P C, Pereira J A. Drying curves and water activity evaluation of dried banana. In 14th International Drying Symposium, 2004, pp. 22-25 [21] Mclaughlin C P, Magee T R. The determination of sorption isotherm and the isosteric heats of sorption for potatoes. Journal of Food Engineering, 1998, 35(3):267-280

[22] Sadler G D, Murphy P A. pH and titratable acidity. In S. S. Nielson (Ed.), Food analysis. New York: Springer Science, 2010, pp. 219-238

[23] Underhill J E. pH without pain. The Grapevine: A newsletter for winemakers in British Columbia. 1989

[24] Malundo M, Shewfelt R, Scott J. Flavor quality of fresh tomato (Lycopersicon esculentum Mill.) as affected by sugar and acid levels. Postharvest Biology and Technology, 1995, 6(1-2):103-110

[25] Ashebir D, Jezik K, Weingartemann H, Gretzmacher R. Change in color and other fruit quality characteristics of tomato cultivars after hot-air drying at low final-moisture content. International Journal of Food Sciences and Nutrition, 2009, 60(7):308-315

[26] Sogi D S, Siddiq M, Greiby I, Dolan K D. Total phenolics, antioxidant activity, and functional properties of 'Tommy Atkins' mango peel and kernel as affected by drying methods. Food Chemistry, 2013, 141(3):2649-2655

[27] Adamczak A, Buchwald W, Kozlowski J, Mielcarek S. The effect of thermal and freeze drying on the content of organic acids and flavonoids in fruit of European cranberry (Oxycoccus palustris Pers.). Herba Polonica, 2009, 55(3):94102

[28] Owusu J, Ma H, Wang Z, Amissah A. Effect of drying methods on physicochemical properties of pretreated tomato (lycopersicon esculentum mill.) slices. Croatian Journal of Food Technology, Biotechnology and Nutrition, 2012, 7(1-2):106-111 
[29] Dairy Products Technology Center. Dairy ingredients fax: Bulk density. San Luis Obispo: California Polytechnic State University, 2001

[30] Rawal R, Masih D. Study of the effect on the quality attributes of apple pomace powder prepared by two different dryers. IOSR Journal of Agriculture and Veterinary Science, 2014, 7(8):54-61

[31] Adebowale K O, Olu-Owolabi B I, Olayinka O O, Olayide S L. Effect of heat moisture treatment and annealing on physicochemical properties of red sorghum starch. African Journal of Biotechnology, 2005, 4(9):923-933

[32] Obatolu V A, Fasoyiro S B, Ogunsunmi L O. Processing and functional properties of yam beans (Sphenostylis sternocarpa). Journal of Food Processing and Preservation, 2007, $31(2): 240-249$

[33] Houson P, Ayenor G S. Appropriate processing and food functional properties of maize flour. African Journal of Science and Technology, 2002, 3(1):126-131

[34] Obasi N E, Unamma N C, Nwofia G E. Effect of dry heat pre-treatment (toasting) on the cooking time of cowpeas (Vigna unguiculata L. Walp). Nigerian Food Journal, 2014, 32(2):16-24

[35] Chau C F, Cheung P C K, Wong Y S. Functional properties of protein concentrates from three Chinese indigenous legume seeds. Journal of Agricultural and Food Chemistry, 1997, 45(7):2500-2503

[36] Adebowale K O, Lawal O S. Comparative study of the functional properties of Bambara groundnut jack bean and mucuna bean flours. Food Research International, 2004, 37(4):355-365

[37] Henriques F, Guiné R, Barroca M J. Chemical properties of pumpkin dried by different methods. Croatian Journal of Food Technology, Biotechnology and Nutrition, 2012, 7(1-2):98-105

[38] Moreira R, Chenlo F, Torres M D, Rama B, Arufe S. Air drying of chopped chestnuts at several conditions: effect on colour and chemical characteristics of chestnut flour. International Food Research Journal, 2015, 22(1):407-413 
[39] Nomura K, Ogasawara Y, Uemukai H, Yoshida M. Change of sugar content in chestnut during low temperature storage. Postharvest Physiology of Fruits, 1994, 398:265-276

[40] Oke M O, Workneh T S. A review on sweet potato postharvest processing and preservation technology. African Journal of Agricultural Research, 2013, 8(40):4990-5003

[41] Correia P, Beirão-da-Costa M L. Effect of drying temperatures on starch-related functional and thermal properties of acorn flours. Journal of Food Science, 2012, 76(2):196-202

[42] Liu Q. Understanding starches and their role in food. In S. Cui (Ed.), Food carbohydrates: Chemistry, physical properties, and applications. New York: CRC Press, 2005, pp. 309-349

[43] Osorio-Diaz P, Bello-Perez L A, Sayago-Ayerdi S G, Benitez-Reyes M D P, Tovar J, Paredes-Lopes O. Effect of processing and storage time on in vitro digestibility and resistant starch content of two bean (Phaseolus vulgaris L.) varieties. Journal of the Science of Food and Agriculture, 2003, 83(12):1283-1288

[44] Tharanathan R N, Mahadevamma S. Grain legumes-A boon to human nutrition. Trends in Food Science \& Technology, 2003, 14(12):507-518

[45] Rewthong O, Soponronnarit S, Taechapairoj C, Tungtrakul P, Prachayawarakorn S. Effects of cooking, drying and pretreatment methods on texture and starch digestibility of instant rice. Journal of Food Engineering, 2011, 103(3):258-264

[46] Sapii A T, Muda F. Guidelines of fruit maturity and harvesting. Putrajaya: Malaysian Agricultural Research and Development Institute, 2005

[47] Bainbridge Z, Tomlins K, Welling K, Westby A. Methods of assessing quality characteristics of non-grain starch staples. Chatham: Natural Resource Institute, 1996 [48] Narayana K, Rao M N. Effect of partial proteolysis on the functional properties of winged bean (Psophocarpus tetragonolobus) flour. Journal of Food Science, 1984, 49(3):944-947

[49] Chow P S, Landhäusser S M. A method for routine measurements of total sugar and starch content in woody plant tissues. Tree Physiology, 2004, 24(10):1129-1136

[50] Goñi I, Garcia-Alonso A, Saura-Calixto F. A starch hydrolysis procedure to estimate glycemic index. Nutrition Research, 1997, 17(3):427-437 
[51] Goni I, Garcia-Diz L, Mañas E, Saura-Calixto F. Analysis of resistant starch: A method for foods and food products. Food Chemistry, 1996, 56(4):445-449

[52] Beuchat L R. Functional and electrophoretic characteristics of succinylated peanut flour protein. Journal of Agricultural and Food Chemistry, 1977, 25(2):258-261

\section{How to cite this article:}

Ho LH, Pang WP, Tan TC, Mustafa KA.Effects of drying conditions on the physicochemical and functional properties of red- and yellow-fleshed watermelon rinds flour. J. Fundam. Appl. Sci., 2017, 9(2S), 898-923 